\title{
Biological Significance of the Thermodynamic Stability of CRISPR Structures Associated with Unconventional
}

\section{Functions}

\author{
Carla A. Lossada ${ }^{1(\mathbb{D})}$, Francelys V. Fernández-Materán ${ }^{1(\mathbb{D})}$, María M. Parra ${ }^{2}{ }^{\mathbb{D}}$, Luis S. Moncayo ${ }^{3(\mathbb{D})}$, \\ Freddy Romero ${ }^{4 \mathbb{C}}$, José L. Paz ${ }^{5 \mathbb{D}}$, Joan Vera-Villalobos ${ }^{6}{ }^{\mathbb{D}}$, Aleivi E. Pérez ${ }^{7 \mathbb{C}}$, Edgar Portillo ${ }^{\mathbb{D}}$, \\ Ysaias J. Alvarado ${ }^{1, *}\left(\mathbb{D}\right.$, Lenin A. González-Paz ${ }^{2, *}$ (i)
}

1 Laboratorio de Caracterización Molecular y Biomolecular, Centro de Investigación y Tecnología de Materiales (CITeMA), Sección de Microbiología Molecular y Biofísica, Instituto Venezolano de Investigaciones Científicas (I.V.I.C) - Zulia, Maracaibo, Venezuela

2 Laboratorio de Genética y Biología Molecular (L.G.B.M), Departamento de Biología, Facultad Experimental de Ciencias (F.E.C), Universidad del Zulia (L.U.Z), Maracaibo, Republica Bolivariana de Venezuela

3 Universidad Católica de Cuenca, Ecuador

4 Baylor College of Medicine, USA

5 Departamento de Física, Escuela Politécnica Nacional, Ladrón de Guevara, E11-253,170517, Quito, Ecuador

6 Laboratorio de Desarrollo de Métodos y Gestión de la Calidad, Departamento de Ciencias Biológicas. Facultad de Ciencias de la Salud, Universidad Técnica de Manabí, Ecuador

7 Laboratorio de Microbiología General (L.M.G), Departamento de Biología. Facultad Experimental de Ciencias (F.E.C), Universidad del Zulia (L.U.Z), Maracaibo, Venezuela

8 Laboratorio de Protección Vegetal, Centro de Estudios Botánicos y Agroforestales, Instituto Venezolano de Investigaciones Científicas (I.V.I.C), Zulia, Maracaibo, República Bolivariana de Venezuela

* Correspondence: lgonzalezpaz@gmail.com (L.G.); alvaradoysaias@gmail.com (Y.A.).;

Scopus Author ID 6602882448

Received: 1.10.2020; Revised: 22.10.2020; Accepted: 24.10.2020; Published: 26.10.2020

Abstract: The clustered regularly interspaced short palindromic repeats (CRISPR) are genetic sequences that conventionally confer immunity to prokaryotes against invading genetic elements. The objective of this work was to perform an analysis of these sequences at the thermodynamic level, determining the minimum free formation energy (MFE) of the direct repeats (DR) and of the complete CRISPR structures that include the spacer sequences (DRSP), and to analyze the possible relationship between the energetics of formation and the associated non-canonical mechanism in 30 prokaryotic reported genomes, to understand their biological significance. We found that all non-conventional CRISPR was thermodynamically more stable and spontaneous in their formation than the rest of the adjacent CRISPRs. The bioinformatics strategy applied allowed us to conclude that all nonconventional CRISPR were those with MFE values of higher magnitude and negative sign, that is, the structures most favored thermodynamically for their formation. These findings could only be established reliably with DRSP, in contrast to results obtained with their respective DR. Moreover, spontaneity was seen as not only associated with a particular function but with aspects related to transcription. We propose to consider the analysis of the DRSP as a strategy to discriminating that CRISPR with determinant roles in microorganisms.are not presented and substantiated in the main text and should not exaggerate the main conclusions.

Keywords: MFE; CRISPR; transcription.

(C) 2020 by the authors. This article is an open-access article distributed under the terms and conditions of the Creative Commons Attribution (CC BY) license (https://creativecommons.org/licenses/by/4.0/). 


\section{Introduction}

The bioadhesion of Pseudomonas aeruginosa and the study of DMS3 warm phage infections have been characterized in different ways [1,2,3], especially by studying the CRISPR influence in those processes; nevertheless, the thermodynamics formation properties of associated CRISPR matrices is not yet understood. A wide variety of virulence factors has been described in the bacteria $P$. aeruginosa. These include the ability to adhere to surfaces and mucous membranes. This adherence gives the bacteria the strength to invade and proliferate in the host organism defending itself from immune systems and being unnoticed, especially in fibrocystic patients $(\mathrm{CF})[4,5,6]$.

However, previous works have not considered predicting the secondary structure of the RNA species from prokaryotic precursors associated with bioadhesion in P. aeruginosa. On the other hand, determining the thermodynamic stability of CRISPR systems should be considered. This can be done by calculating the minimum free energy (MFE) of formation, either from the sequences called direct repeats (DR) [7-13] or from the complete CRISPR structure composed by DR and the spacer sequences (DRSP) [14]. In P. aeruginosa, one of the CRISPR structures has shown to be responsible for modulating behaviors associated with bioadhesion in the DMS3 lysogens instead of conferring immunity against invasive genetic material $[16,17,18]$. So, understanding the relationship between the depicted processes and the thermodynamic properties on the CRISPR structures would give a distinct perspective.

In CF patients, the strains of $P$. aeruginosa that produce biofilms colonize the respiratory tract very efficiently by promoting the appearance of mucoid variants of this bacterium. Once the infection of those mucoid variants is established in the patient lungs, it persists until the final stage of the disease because the immune system is unable to eliminate the bacteria. Up today, there are no effective treatments against strains with a mucoid phenotype. The characterization of these variants CRISPR is important. Their ability to modulate bioadhesion, as well as the production of exopolysaccharides, can be a determining factor in indicating both the stages of diseases such as CF and their possible treatments [19]. Also, several authors have hypothesized an association between the presence of the CRISPR system and their role in microbial genetic regulation and group behaviors in prokaryotes $[20,21,22]$.

The possibility of the existence of CRISPR structures with non-conventional functions was initially explored by several authors. This was done by searching spacers with homology in their sequences (or self-directed spacers) in prokaryotic genomes, a phenomenon known as "autoimmunity" [23]. The possibility of the existence of self-directed spacers associated with some type of regulation has been ignored, especially since the possible mechanisms of selfregulation of "autoimmunity" have already been suggested [24,25]. The role of CRISPR in the prevention of the induction of latent viruses, the control of the expansion of mobile genetic elements [26], genetic regulation, control of group behavior, expression of virulence genes, genome remodeling, and DNA repair $[27,28,29]$ have proposed the idea of a duality function of these systems [30]. This duality could partially explain why this valuable system created to combat invading genetic materials (i.e., phages and plasmids) is not present in all prokaryotic genomes. Some bacterial genomes $[31,32]$ lack the conventional function of immunity and has perhaps adapted to selective pressures such as the use of antibiotics [33,34] fulfilling other roles from symbiosis [35] to their path to becoming part of the regular microbiota of the human being [36]. Therefore, in this study, we consider the not immunity-related CRISPR structures 
as unconventional ones, including those associated with the so-called "autoimmunity" for presenting atypical mechanisms.

As mentioned before, the understanding of CRISPR biology at the transcriptional level is important. As far as we have known, there are no studies of CRISPR structures and their association with non-conventional functions. Also, the prediction of the secondary structure and determination of the thermodynamics of the formation of those CRISPR structures is still unknown $[20,22,27,28]$. Since a possible structural and functional relationship between the secondary structures derived from the DRs of various CRISPRs has been postulated [26], the objectives of this work were to determine if the CRISPR structure associated with bioadhesion in $P$. aeruginosa is thermodynamically the most stable concerning the rest of the CRISPR structures present in the genome and to evaluate any relationship between the thermodynamics of CRISPR structure formation and its non-conventional functions.

\section{Materials and Methods}

A thermodynamic and bioinformatic theoretical study of CRISPR structures related to reported unconventional functions $[20,22]$ was performed. The complete genomic sequences were obtained from the GenBank/NCBI database (https://www.ncbi.nlm.nih.gov/) [36-39]. The CRISPR loci were identified using CRISPRFinder (http://crispr.i2bc.paris-saclay.fr/) and the CRISPRdb information (http://crispr.i2bc.paris-saclay.fr/crispr/) [40]. Genomes with a minimum of two CRISPR structures were considered for comparison. The resulting matrices were designated in this work as CRISPR1 and CRISPR2 according to their association with non-conventional/conventional functions, respectively (see Table 1). These results were obtained after the prediction of the psiRNA transcribed by the CRISPR loci as described for the analysis of the complete structures [14].

The prediction of secondary RNA structures, as well as the minimum free energy (MFE) of formation, were determined by RNAfold (http://rna.tbi.univie.ac.at/cgibin/RNAWebSuite/RNAfold.cgi) [41]. The proposed criterion for the study of the secondary structures of prokaryotic siRNA precursors (psiRNA) transcribed by the CRISPR loci was based on the comparison of the thermodynamic formation of the DR $[7,12,26]$ and the DRSP structures [14]. The organisms, as well as the MFE of the psiRNAs are shown in Table 1. The correlation coefficient was determined, and a T-Test was applied to establish whether there are correlations and differences between the thermodynamic parameters calculated after the determination of the MFE of formation of their DRs and DRSP matrices, respectively. All analyzes were performed with the IBM SPSS-23 statistical package.

\section{Results and Discussion}

\subsection{Thermodynamics of unconventional CRISPR structures.}

The resulting sequences (30 strains) reported in the literature were characterized by presenting CRISPR structures associated with unconventional functions or not involved with the mechanism of acquired immunity $[42,43]$. We found that all non-conventional CRISPR structures, including the one associated with modulation of the bioadhesion of $P$. aeruginosa, had the highest MFE values with a negative sign. These results reveal the most favored structures for their formation in terms of thermodynamics. The calculation of MFE associated with the spontaneity of the CRISPR structures formation suggests that the secondary RNA structures predicted with unconventional functions are thermodynamically more stable than the 
other neighboring structures related to the conventional role. For example, comparing two of the CRISPR structures found in the mucoid variant of $P$. aeruginos $a$ with an associated matrix for the modulation of bioadhesion, an increase of the thermodynamic formation can be seen compared with those structures not associated with the formation of biofilms.

In $P$. aeruginosa we also examined the MFE for each probable structure, the TA (thermodynamic assembly of the RNA structures), and the position of the centroid (CP) (Figure 1A,B). No significant disparity between the thermodynamic characteristics calculated in the matrix designated as CRISPR1 was found and can be considered as evidence of the stability of the secondary structure transcribed from the pre-psiRNA related to the formation of biofilms. In contrast, the predicted variations in the CRISPR 2 structure. Similar results were obtained in most of the DRSP structures in this study. In all cases, CRISPRs with possible non-canonical functions were always the most favored thermodynamically compared to adjacent matrices. These results were observed independently of whether the DRSP structure was directly involved in possible regulatory functions or if its DR participated indirectly as possible ribosomal binding sites [44], the presence of self-directed spacers [22,45], or the intervention of their cas genes [46,47,48].

A

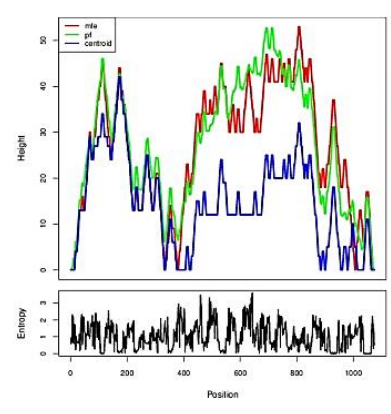

C

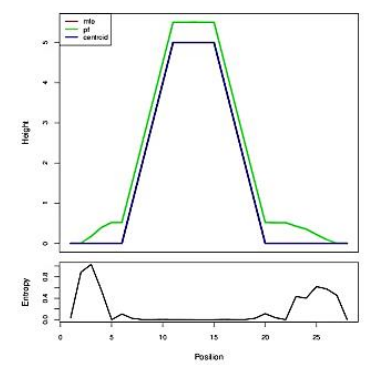

B

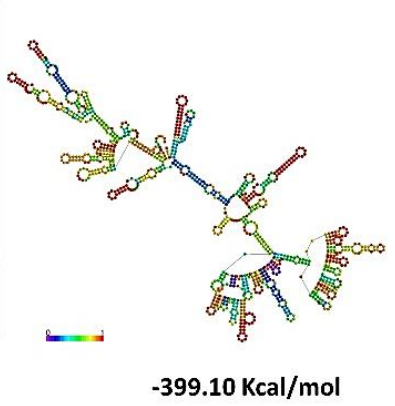

$-399.10 \mathrm{Kcal} / \mathrm{mol}$

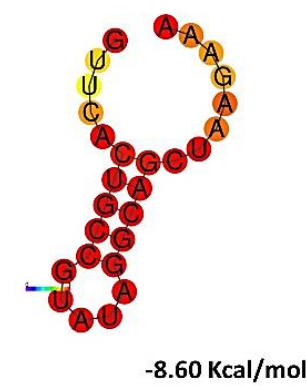

D
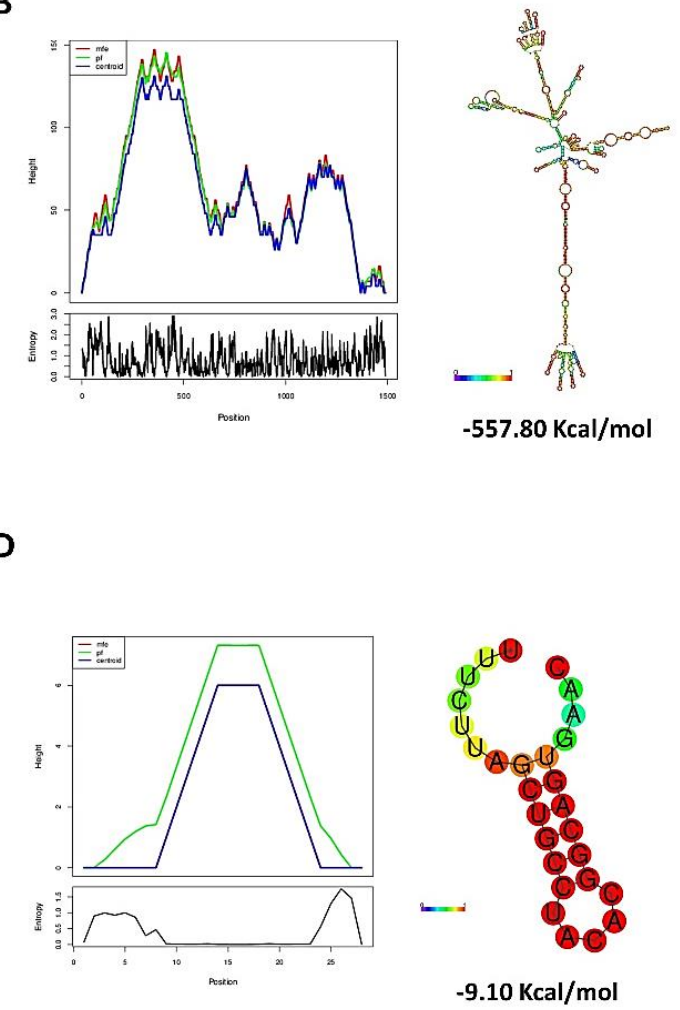

Figure 1. Secondary predicted RNA structure of the loci CRISPR in P. aeruginosa. The prediction of secondary RNA structures, as well as the minimum free energy (MFE) of formation, was determined by RNAfold. (A) and (B) loci CRISPR1 and 2, and the DR consensus sequence of CRISPR1 (C) and CRISPR2 (D) in P. aeruginosa, respectively. It is also shown on the left side of each structure a graphic representation of the MFE, the thermodynamic set of RNA structures, and the centroid structure. In addition, positional entropy for each position and $\Delta \mathrm{G}$ in $\mathrm{Kcal} / \mathrm{mol}$ are also shown.

The results allow explaining that the CRISPR structure associated with bioadhesion in $P$. aeruginosa corresponds to the thermodynamically more stable structure (MFE $<0)$ compared to the rest of the CRISPR structures present in its genome. On the other hand, our results show a relationship between the lowest value of MFE for the formation of CRISPR structures (thermodynamically more stable structures) and their non-canonical functions. These results 
could provide information based on energetic characteristics to elucidate these results, provide some information based on energetic characteristics, and elucidate the influence of some CRISPR structures present in systems associated with modulation of group behavior. Also, they can be used for other structures whose participation is not clear yet, as in the case of $M$. Xanthus [44], which is a microorganism with four CRISPR systems. In M. xanthus, the I-C type CRISPR system is responsible for regulating the sporulation cascade, but no clear participation of any of its CRISPR matrices have been found. Even though their cas genes have been associated with a matrix with 22 DR classified as CRISPR3 [20].

Interestingly, the calculation of the thermodynamics of formation of the four structures in $M$. xanthus, showed that the CRISPR thermodynamically most favored for its formation corresponds to CRISPR1 and 4 (classified in this study as CRISPR1 and 2, respectively). The CRISPR3 (with a matrix with DR 22) represented one of the least thermodynamically favored in this organism [38]. CRISPR3 has been reported as a type I-A recently and suggested that the I-C type corresponds to the CRISPR 1 matrix (the energetically most favored) and that the cluster of genes involved in unconventional function is adjacent to CRISPR4 type III-B. Therefore, regardless of the correct classification of the CRISPR systems present in M. xanthus, the most favored thermodynamically CRISPR structures were found flanking the genes associated with the modulation of group behavior. Possibly their spontaneity of formation influences the transcriptional activity of the non-canonical loci.

\subsection{Biological role of the adequate determination of the thermodynamic of CRISPR structures.}

After the thermodynamic calculation based on the DR [7-12] for the comparative analysis of the MFE of formation of the CRISPR matrices and the consequent establishment of the thermodynamically more spontaneous structures, we observe magnitudes for the thermodynamic difference $\Delta G_{d}=\mid \Delta G_{(D R 1)}-\Delta G_{(D R 2)}$ I, which are in the range of $0 \leq \Delta \mathrm{Gd}$ $\leq 15.6 \mathrm{Kcal} / \mathrm{mol}$, and the average was $2.5 \mathrm{Kcal} / \mathrm{mol}$. This small difference makes difficult the discrimination from a thermodynamic point of view between the CRISPR structures from those that are not, according to our criteria. These results agree with the reported thermodynamic values of MFE formation, considering only the DR sequences. On the other hand, applying the same strategy and considering the DRSP [10] for the structures found in the 30 resulting sequences of this work, an MFE with clear differences between the values for the CRISPR1 and CRISPR2 structures was obtained. This difference in free energy, $\Delta G_{D}=1 \Delta G_{(C R I S P R 1)}-$ $\Delta G_{\text {(CRISPR2) }}$ I, was in the range of $21.4 \leq \Delta \mathrm{GD} \leq 2678.8 \mathrm{Kcal} / \mathrm{mol}$, and with an average of $\Delta \mathrm{GD}$ $750.03 \mathrm{Kcal} / \mathrm{mol}$ (see Table 1 ).

These magnitudes clearly allow us to discern the stability between different CRISPR structures. This observation is reinforced because we found no significant differences between the formation thermodynamics from DR1 and DR2 ( $p>0.01$ ), whereas, conversely, significant differences between the formation thermodynamics calculated energies of DRSP matrices $(\mathrm{p}<0.01)$ was observed.

Table 1.Thermodynamic stability of CRISPR structures associated with unconventional functions.

\begin{tabular}{|c|c|c|c|c|c|c|c|c|c|}
\hline \multirow{2}{*}{ Sp. } & \multirow{2}{*}{$\begin{array}{l}\text { CRISPR- } \\
\text { Cas type }\end{array}$} & \multirow{2}{*}{$\begin{array}{l}\text { Description of the target gene or } \\
\text { associated function }\end{array}$} & \multicolumn{3}{|c|}{$\bullet \Delta \mathrm{G}_{\mathrm{DRi}}(\mathrm{Kcal} / \mathrm{mol})$} & \multicolumn{3}{|c|}{$\Delta \mathbf{G}_{\text {CRISPRi }}(\mathrm{Kcal} / \mathbf{m o l})$} & \multirow[b]{2}{*}{ Ref. } \\
\hline & & & DR1 & DR2 & $\Delta \mathbf{G}_{\mathbf{d}}$ & CRISPR1 & CRISPR2 & $\Delta \mathbf{G}_{\mathbf{D}}$ & \\
\hline $\mathrm{Bad}$ & Dvulg & $\begin{array}{l}\text { Self-targeting for 3-Phosphoshikimate } \\
\text { 1-arboxyvinyltransferase }\end{array}$ & -15.9 & -9.20 & 6.7 & -2455.80 & -65.50 & 2390.3 & 11 \\
\hline Blo & Nmeni & $\begin{array}{lll}\text { Self-targeting for } & f h u & \text { operon } \\
\text { transcription regulator } & & \\
\end{array}$ & -4.50 & -0.60 & 3.9 & -748.30 & -29.50 & 718.8 & 11 \\
\hline Cje & Nmeni & $\begin{array}{lll}\text { Cas9-dependent } & \text { cell } & \text { surface } \\
\text { modification } & & \end{array}$ & $0.00^{\dagger}$ & 0.00 & 0.0 & -36.70 & -7.50 & 29.2 & 10 \\
\hline \multicolumn{9}{|c|}{ https://biointerfaceresearch.com/ } & 0385 \\
\hline
\end{tabular}




\begin{tabular}{|c|c|c|c|c|c|c|c|c|c|}
\hline \multirow[b]{2}{*}{ Sp. } & \multirow{2}{*}{$\begin{array}{l}\text { CRISPR- } \\
\text { Cas type }\end{array}$} & \multirow{2}{*}{$\begin{array}{l}\text { Description of the target gene or } \\
\text { associated function }\end{array}$} & \multicolumn{3}{|c|}{$\bullet \Delta \mathbf{G}_{\mathrm{DRi}}(\mathrm{Kcal} / \mathrm{mol})$} & \multicolumn{3}{|c|}{$\Delta \mathbf{G}_{\text {CRISPRi }}(\mathrm{Kcal} / \mathbf{m o l})$} & \multirow{2}{*}{ Ref. } \\
\hline & & & DR1 & DR2 & $\Delta \mathbf{G}_{\mathbf{d}}$ & CRISPR1 & CRISPR2 & $\Delta \mathbf{G}_{\mathrm{D}}$ & \\
\hline Cli & Csx.RAMP & $\begin{array}{l}\text { Self-targeting for succinyl-CoA } \\
\text { synthetase, beta subunit }\end{array}$ & -1.90 & -0.70 & 1.2 & -1891.70 & -413.50 & 1478.2 & 11 \\
\hline $\mathrm{Cph}$ & Unknown & $\begin{array}{ll}\begin{array}{l}\text { Self-targeting } \\
\text { amidophosphoribosyltransferase }\end{array} & \text { for } \\
\end{array}$ & -16.0 & -0.40 & 15.6 & -1143.90 & -162.90 & 981.0 & 11 \\
\hline Cte & Csx.tneap & Self-targeting for several genes* & -1.30 & 0.00 & 1.3 & -442.00 & -103.60 & 338.4 & 11 \\
\hline E sp. & Y pest & Self-targeting for FdrA family protein & $-\overline{8.60^{\dagger}}$ & -8.60 & 0.0 & -420.80 & -354.77 & 66.0 & 11 \\
\hline Eco & E coli & DNA repair by Cas 1 & $\overline{4}-20^{\dagger}$ & -14.2 & 0.0 & -361.80 & -168.30 & 193.5 & 10,11 \\
\hline Fps & Nmeni & $\begin{array}{lll}\begin{array}{l}\text { Objective } \\
\text { determined }\end{array} & \text { self-targeting } & \text { not } \\
\end{array}$ & -3.00 & 0.00 & 3.0 & -265.30 & -46.00 & 219.3 & 11 \\
\hline Ftu & Nmeni & $\begin{array}{ll}\text { Cas9-mediated downregulation } & \text { of } \\
\text { BLP production } & \end{array}$ & -2.70 & -4.20 & 1.5 & -165.30 & -97.60 & 67.7 & 10 \\
\hline Fal & E coli & $\begin{array}{l}\text { Self-targeting for putative acyl-CoA } \\
\text { dehydrogenase }\end{array}$ & $\overline{5.10^{\dagger}}$ & -15.1 & 0.0 & -3380.00 & -976.40 & 2403.6 & 11 \\
\hline F sp. & Dvulg & $\begin{array}{llll}\begin{array}{l}\text { Self-targeting } \\
\text { adenylation }\end{array} & \text { for } & \text { amino } & \text { acid } \\
\end{array}$ & -15.5 & -22.2 & 6.7 & -1284.20 & -875.20 & 409.0 & 11 \\
\hline Gre & Unknown & $\begin{array}{l}\text { Self-targeting for 2-methylisocitrate } \\
\text { lyase }\end{array}$ & -14.3 & -12.9 & 1.4 & -940.40 & -863.10 & 77.3 & 11 \\
\hline Mhu & (a) & Dibydroorotate dehydrogenace $1 \mathrm{R}$ & -8.60 & -3.80 & 4.8 & -1554.30 & -1189.00 & 365.3 & 11 \\
\hline Sgr & 1 & lyl-transferase & -12.3 & 3.2 & 0.9 & & & & 11 \\
\hline Lmo & $\begin{array}{l}\text { Orphan/CRI } \\
\text { SPR }\end{array}$ & $\begin{array}{l}\text { ion of feo } \mathrm{AB} \text { operon by partial } \\
\text { mentarity }\end{array}$ & -1.20 & -9.60 & 8.4 & -51.90 & -30.50 & 21.4 & 10 \\
\hline $\mathrm{Mfl}$ & Dvulg & $\begin{array}{l}\text { Self-targeting for glycosyltransferase, } \\
\text { group } 1\end{array}$ & -13.1 & -14.4 & 1.3 & -2806.30 & -797.70 & 2008.6 & 11 \\
\hline Mga & Nmeni & $\begin{array}{l}\text { Self-targeting for } \quad \text { ParC/GyrA; } \\
\text { topoisomerase IV subunit A }\end{array}$ & -5.10 & -0.30 & 4.8 & -1051.20 & -9.80 & 1041.4 & 11 \\
\hline Mxa & Dvulg & Regulation of fruiting body formation & -12.5 & -7.80 & 4.7 & -1755.40 & -908.00 & 847.4 & 10,11 \\
\hline $\mathrm{Nfa}$ & E coli & $\begin{array}{lll}\begin{array}{l}\text { Self-targeting } \\
\text { regulator }\end{array} & \text { for } & \text { transcriptional } \\
\end{array}$ & -15.1 & -14.5 & 0.6 & -968.70 & -378.80 & 589.9 & 11 \\
\hline Pat & $Y$ pest & $\begin{array}{l}\text { ll of genomic regions by self- } \\
\mathrm{g}\end{array}$ & -9.10 & -8.60 & 0.5 & -646.20 & -199.10 & 447.1 & 10 \\
\hline Ppr & Ecoli & Self-targeting for several genes** & -14.3 & -12.2 & 2.1 & -1267.10 & -42.00 & 1225.1 & 11 \\
\hline Pgi & RAMP & $\begin{array}{lll}\begin{array}{l}\text { Self-targeting } \\
\text { dehydrogenase }\end{array} & \text { for saccharopine } \\
\end{array}$ & -3.90 & -3.80 & 0.1 & -406.30 & -152.00 & 254.3 & 11 \\
\hline $\mathrm{Pae}$ & Ypest & Based on partial complementarity & -9.10 & -8.60 & 0.5 & -557.80 & -399.10 & 158.7 & 10 \\
\hline Pho & Unknown & $\begin{array}{lll}\begin{array}{l}\text { Objective of } \\
\text { determined }\end{array} & \text { self-targeting not } \\
\end{array}$ & -2.10 & -3.40 & 1.3 & -1235.00 & -495.40 & 739.6 & 11 \\
\hline Pfu & RAMP & Cleavage of complementary mRNA & 0.00 & 0.00 & 0.0 & -743.05 & -571.70 & 171.4 & 10 \\
\hline Rte & M tube & $\begin{array}{l}\begin{array}{l}\text { Self-targeting for PAS domain- } \\
\text { containing protein }\end{array} \\
\end{array}$ & -8.10 & -6.10 & 2.0 & -5416.70 & -3428.20 & 1988.5 & 11 \\
\hline Sar & E coli & $\begin{array}{lll}\begin{array}{l}\text { Objective of } \\
\text { determined }\end{array} & \text { self-targeting not } \\
\end{array}$ & -13.4 & -11.6 & 1.8 & -1197.40 & -857.90 & 339.5 & 11 \\
\hline Sav & E coli & $\begin{array}{l}\text { Self-targeting for multidrug resistance } \\
\text { efflux protein }\end{array}$ & -12.6 & -10.9 & 1.7 & -1971.70 & -1213.80 & 769.4 & 11 \\
\hline Ype & $Y$ pest & $\begin{array}{l}\text { Self-targeting for phosphotransferase } \\
\text { enzyme II, a component }\end{array}$ & -9.10 & -8.60 & 0.5 & -141.10 & -53.30 & 87.8 & 11 \\
\hline
\end{tabular}

Bad (NC_008618.1), Blo (NC_004307.2), Cje (NC_002163.1), Cli (NC_010803.1), Cph (NC_010831.1), Cte (NC_004557.1), Esp. (NC_009436.1), Eco (NC_007779.1), Fps (NC_009613.3), Ftu (NC_008601.1), Fal (NC_008278.1), Fsp. (NC_007777.1), Gre (NC_009483.1), Mhu (NC_007796.1), Sgr (NC_010572.1), Lmo (NC_003210.1), Mfl (NC_007947.1), Mga (NC_004829.2), Mxa (NC_008095.1), Nfa (NZ_LN868938.1), Pat (NZ_CP007744.1), Ppr (NC_008609.1), Pgi (NC_010729.1), Pae (NC_002516.2), Pho (NC_000961.1), Pfu (NC_003413.1), Rte (NC_009767.1), Sar (NC_009953.1), Sav (NC_003155.5), Ype (NC_003143.1), are the acronyms of Bifidobacterium adolescentis, Bifidobacterium longum, Campylobacter jejuni, Chlorobium limícola, Chlorobium phaeobacteroides, Clostridium tetani, Enterobacter sp., Escherichia coli, Flavobacterium psychrophilum, Francisella tularensis, Frankia alni, Frankia sp., Geobacteruranii reducens, Methanospirillum hungatei, Streptomyces griseus, Listeria monocytogenes, Methylobacillus flagellatus, Mycoplasma gallisepticum, Myxococcus xanthus, Nocardia farcinica, Pectobacterium atrosepticum, Pelobacter propionicus, Porphyromonas gingivalis, Pseudomonas aeruginosa, Pyrococcus horikoshii, Pyrococcus furiosus, Roseiflexuscas tenholzii, Salinispora arenicola, Streptomyces avermitilis, and Yersinia pestis respectively species (Sp) found by their respectively accesion number at the GenBank. - $\triangle \mathrm{G}_{\mathrm{DR}} \mathrm{w}$ where $\mathrm{i}=1$ or 2 , CRISPR-Cas, clustered regularly interspaced short palindromic repeats-CRISPR-associated proteins; DR1 and DR2, direct repeats (DR) of CRISPR1 and CRISPR2; CRISPR1 and CRISPR2, CRISPR structures designated by the authors as 1 and 2; $\bullet \Delta \mathrm{G}_{\mathrm{DR}}$; minimum free energy (MFE) of the consensus sequence of DRi; $\Delta \mathrm{G}_{\mathrm{CRISPR}}$ Where $\mathrm{i}=1$ or 2, MFE of the complete CRISPR structure.; DR1 vs DR2, $(p>0.01)$; CRISPR1 vsCRISPR2, $(p<0.01)$; DR1 vs CRISPR1, $(r<0.4)$; DR2 vs CRISPR2, $(r<0.2)$; $\Delta$ G of similar DR1 and DR2 in the same CRISPR structure and, therefore, this are not thermodynamically differentiable with the determination of the MFE starting only from the DR; $\Delta G_{d}=\left|\Delta G_{(D R 1)}-\Delta G_{(D R 2)}\right| ; \Delta G_{D}=\left|\Delta G_{(C R I S P R 1)}-\Delta G_{(C R I S P R 2)}\right|$; *Self-targeting for putative S-layer, stage IV sporulation protein A,DNA mismatch repair protein, phosphoribosylformylglycinamidine synthase II, and putative sporulation sigma-E factor processing; ${ }^{* *}$ Self-targeting for histidyl-tRNAsynthetase, hydrophobe/amphiphile efflux-1 (HAE1) family, DNA topoisomerase I and RND efflux system outer membrane lipoprotein.

These results demonstrate that the discriminative biological value of the DRSP structures is strong and should not be ignored, especially because we found a very low correlation between the formation thermodynamics calculated from the DR and its corresponding CRISPR matrix $(r<0.4$ for CRISPR1 and $r<0.2$ for CRISPR2). Therefore, we 
consider determining $\triangle \mathrm{GD}$ in future studies to establish stability between CRISPR matrices. Additionally, when carrying out an APC, we found that the thermodynamic stability of the complete CRISPR matrices can explain about $40 \%$ of the variability observed. A result that corresponds to the obtained through a DCA with which we were able to determine that the thermodynamic stability of complete CRISPRs has the highest qualifying and discriminatory weight of the phenomenon, under the conditions of our study.

Studies on the entropic contribution to the formation of DRSP structures are being carried out by our group. In this direction, we present a preliminary analysis of the difference in entropy of the DRSP structures of $P$. aeruginosa. The results show that the entropic contribution to the formation of the structure as a function of the position of the nucleotides in the CRISPR1 matrix has a higher magnitude and lower fluctuation compared to the behavior of positional entropy per nucleotide for CRISPR2, whose magnitude is lower and has a greater fluctuation of this property with the position of the nucleotides (see Figure 1A, B). Interestingly, in the same figure, the positional entropy per nucleotide associated with the DR structures reach lower values as expected due to their size and less flexibility (few degrees of freedom) than those obtained for the larger CRISPR structures with greater flexibility. Also, the difference in entropy between the DR structures has a value very close to zero with respect to the position of the nucleotides (see Figure 1C,D). Relating entropy as a parameter of structural and transcriptional flexibility with the activity of CRISPR systems becomes of interest to us.

\subsection{Discussion.}

Sequences of $P$. aeruginosa did not show significant differences between the thermodynamic characteristics in the matrix CRISPR1, contrasting to variations in the CRISPR2, and analogous results obtained in most of the DRSP. These patterns have been described in other CRISPR with thermodynamic characteristics that have been related to stability $[14,15,45]$. Determining $\Delta \mathrm{GD}$ to establish stability between CRISPR matrices becomes evident if we take into account that the formation MFE exhibited by DR1 and DR2 of the species Enterobacter sp., F. alni, C. jejuni, P. furiosus, and E. coli present very similar $\Delta \mathrm{G}$ to each other (Table 1). This could be due to the fact that although DR can be used to establish evolutionary relationships [46] and although they can present mutations that generate sequences that are not always true palindromes or symmetrical in their entirety [33] with an important epidemiological and typing value [47]. However, DRs are families of repetitions formed by identical sequences in prokaryotes with constant sizes between 15 and 50 nucleotides, with highly conserved functional relationships [35,48,49]. Therefore, the developed algorithms look for sequences with these characteristics [36,50-55].

This fact would partially explain the lack of differences between the thermodynamics of DR formation. Other studies have observed that RDs can be variable and that several organisms can be grouped based on sequence similarity. Some of these groups have pronounced secondary structures with compensatory base changes [56]. The conservation of RD causes that CRISPR-like transcripts, which are more active or with more spontaneous formation, can be differentiated correctly when evaluating the DRSP that integrates such DR and the spacer sequences [57,58]. The discriminative aspect is more conspicuous in the case of the species M. flagellatus, P. horikoshii, G. bethesdensis, F. novicida, and L. monocytogenes, which present DR with $\Delta \mathrm{G}$ that do not correspond with the thermodynamically more stable CRISPR structures (see Table 1). Therefore, an analysis based only on the thermodynamics of 
DR formation would lead to an unreliable determination of the most active CRISPR structures. This is important at the biological level because CRISPR transcripts play the role of long crRNA precursors. These precursors must then be excised to generate mature RNAs serving as guides for the direction of nucleic acid degradation in both the canonical mechanism $[43,50,59,60]$ and the unconventional $[11,29,61]$.

Our results are consistent with those described in the literature in terms of that structures with a longer stem tend to have a lower MFE representing more stable structures $[8,62]$. In other words, the longer the stem, the greater the stability of the predicted transcribed secondary structure. The increase in the length of the stem is probably related to an increase in the entropy of the system $(\Delta S \geq 0)$. This would be associated with a greater number of electronic, rotational, and vibrational degrees of freedom for a more flexible structure (less rigid). Also, the entropic term $(-\mathrm{T} \Delta \mathrm{S})$ would contribute favorably to the feasibility of the formation of the structure, matching a decrease in the free energy of the system, and possibly favoring the transcription of the CRISPR matrices. Moreover, our results could be related to those obtained in other studies on RNA species such as microRNAs (miRNA) and small interfering RNAs (siRNAs) that show an association between thermodynamic stability and their mechanisms. These studies suggest that the thermodynamic properties of these RNA molecules play a central role in the determination of their functionality, facilitating various aspects associated with the mechanisms of interference $[63,64,65]$.

These observations recall the role of the so-called pre-siRNA [10] or crRNA (CRISPRRNA) [66,67], which must be cleaved enzymatically to generate RNA guides for the direction and degradation of nucleic acids [43,68], analogously to interfering RNA (siRNA) $[42,50,51,69,70]$. This aspect has allowed other authors to formulate the hypothesis that the CRISPR system in prokaryotes could also participate in the regulation of genes based on the conceptual analogy between iRNA and CRISPR [20,69]. Beyond this well-established function, CRISPR-Cas systems have been observed to play alternative roles in physiology. These functions of unconventional CRISPR-Cas systems playing important biologic roles in oxidative stress tolerance, antibiotic resistance, extracellular structure formation, DNA repair, and host-microbe interactions; however, the molecular mechanism of many alternative CRISPR-Cas functions has not yet been fully elucidated [71], that is why, it is important to highlight that although the results obtained in this work are interesting, and highlight a possible correlation or thermodynamic characteristic for the discrimination between the canonical CRISPR structures and the unconventional ones, associated predominantly with virulence factors for the 30 strains considered in the present study, it would be necessary to corroborate through a broader study if our observations on a potential "thermodynamic trace" in CRISPR unconventional, as described in other RNA species [72], are also maintained in canonical CRISPR structures.

Hence, we are currently working on this orientation since it is now possible to assume that the spontaneity involved in the formation of the CRISPR matrices is not associated with a particular function, but with aspects related to the transcription of the loci, that is, probably the most favored thermodynamically minimum energy structures always turn out to be the most active or those with the highest transcriptional activity in response to stress between the systems present in a genome, but regardless of whether these structures have been selected to fulfill a function of immunity or any other of those described as part of their possible duality. Deeper studies to verify the generality of our results are necessary and pertinent due to the fact that the same CRISPR matrix can mediate the immune or regulatory response [73], and this 
phenomenon could be influenced by the structural and longitudinal characteristics of each CRISPR structure due to the spacer sequences stored in these matrices. These sequences of high variability impact the thermodynamics of the overall formation of the primary transcript, and in this sense, if all the CRISPR structures present are transcribed [73], they probably compete with each other through the thermodynamic stability of their formation.

\section{Conclusions}

The bioinformatics strategy applied in this work allows us to conclude that all the nonconventional CRISPR structures, including the one associated with the modulation of the bioadhesion of $P$. aeruginosa, turned out to be those matrices with higher MFE values and negative sign. The results also show that the spontaneity involved in the formation of CRISPR structures is not associated only with a particular function but with aspects related to the transcription of the DRSP. In the absence of experimental data, this strategy would allow discriminating considering both the DRSP and the thermodynamics of formation in those CRISPRs that have determinant roles in the microorganisms from those that do not.

\section{Funding}

This research received no external funding.

\section{Acknowledgments}

This research was financed and funded by CITeMA-I.V.I.C-V.E.N, L.G.B, and L.M.G-F.E.CL.U.Z-VEN.

\section{Conflicts of Interest}

The authors declare no conflict of interest.

\section{References}

1. Cady, K.C.; Toole, G.A. Non-Identity-Mediated CRISPR-Bacteriophage Interaction Mediated via the Csy and Cas3 Proteins. Journal of Bacteriology 2011, 193, 3433-45, https://doi.org/10.1128/JB.01411-10.

2. Cady, K.C.; White, A.S.; Hammond, J.H.; Abendroth, M.D.; Karthikeyan, R.S.G.; Lalitha, P.; Zegans, M.E.; apos; Toole, G.A. Prevalence, conservation and functional analysis of Yersinia and Escherichia CRISPR regions in clinical Pseudomonas aeruginosa isolates. Microbiology Society 2011, 157, 430-437, https://doi.org/10.1099/mic.0.045732-0.

3. Zegans, M.E.; Wagner, J.C.; Cady, K.C.; Murphy, D.M.; Hammond, J.H.; Toole, G.A. Interaction between Bacteriophage DMS3 and Host CRISPR Region Inhibits Group Behaviors of Pseudomonas aeruginosa. Journal of Bacteriology 2009, 191, 210-9, https://doi.org/10.1128/JB.00797-08.

4. Doring, G.; Conway, S.P.; Heijerman, H.G.; Hodson, M.E.; Hoiby, N.; Smyth, A.; Touw, D.J. Antibiotic therapy against Pseudomonas aeruginosa in cystic fibrosis: a European consensus. European Respiratory Journal 2000, 16, 749-67, https://doi.org/10.1034/j.1399-3003.2000.16d30.x.

5. Shaver, C.M.; Hauser, A.R. Relative Contributions of \&lt;em\&gt;Pseudomonas aeruginosa\&lt;/em\&gt; ExoU, ExoS, and ExoT to Virulence in the Lung. Infection and Immunity 2004, 72, 6969-6977, https://doi.org/10.1128/IAI.72.12.6969-6977.2004.

6. Guadarrama, S.; Pulcini, E.; Broadaway, S.C.; Pyle, B.H. Pseudomonas aeruginosa growth and production of Exotoxin A in static and modeled microgravity environments. Gravitational and space biology bulletin : publication of the American Society for Gravitational and Space Biology 2005, 18, 85-86.

7. Shen, J.; Lv, L.; Wang, X.; Xiu, Z.; Chen, G. Comparative analysis of CRISPR-Cas systems in Klebsiella genomes. Journal of Basic Microbiology 2017, 57, 325-336.

8. Li, W.; Bian, X.; Evivie, S.E.; Huo, G.-c. Comparative Analysis of Clustered Regularly Interspaced Short Palindromic Repeats (CRISPR) of Streptococcus thermophilus St-I and its Bacteriophage-Insensitive Mutants (BIM) Derivatives. Current Microbiology 2016, 73, 393-400, https://doi.org/10.1007/s00284-0161076-y. 
9. Rahmatabadi S.; Nezafat N.; Negahdaripour M.; Hajighahramani N.; Morowvat M.H. \& Ghasemi Y. Studying the features of 57 confirmed CRISPR loci in 29 strains of Escherichia coli. J. Basic Microbiol 2016, 56(6): 645-653. https://doi.org/10.1002/jobm.201500707.

10. Wang, P.; Zhang, B.; Duan, G.; Wang, Y.; Hong, L.; Wang, L.; Guo, X.; Xi, Y.; Yang, H. Bioinformatics analyses of Shigella CRISPR structure and spacer classification. World Journal of Microbiology and Biotechnology 2016, 32, https://doi.org/10.1007/s11274-015-2002-3.

11. Negahdaripour, M.; Nezafat, N.; Hajighahramani, N.; Rahmatabadi, S.S.; Ghasemi, Y. Investigating CRISPR-Cas systems in Clostridium botulinum via bioinformatics tools. Infection, Genetics and Evolution 2017, 54, 355-373, https://doi.org/10.1016/j.meegid.2017.06.027.

12. Zhao, X.; Yu, Z.; Xu, Z. Study the Features of 57 Confirmed CRISPR Loci in 38 Strains of Staphylococcus aureus. Front. Microbiol. 2018, 9, https://doi.org/10.3389/fmicb.2018.01591.

13. Scaltriti, E.; Carminati, D.; Cortimiglia, C.; Ramoni, R.; Sørensen, K.I.; Giraffa, G.; Zago, M. Survey on the CRISPR arrays in Lactobacillus helveticus genomes. Letters in Applied Microbiology 2019, 68, 394-402, https://doi.org/10.1111/lam.13128.

14. Chakraborty, S.; Waise, T.; Hassan, F.; Kabir, Y.; Smith, M.; Arif, M. Assessment of the Evolutionary Origin and Possibility of CRISPR-Cas (CASS) Interference Pathway in Vibrio cholerae O395. In silico biology 2009, 9, 245-254, https://doi.org/10.3233/ISB-2009-0402.

15. Sinan, A.-A.; Edze, R.W.; John van der, O.; Stan, J.J.B. Clustered regularly interspaced short palindromic repeats (CRISPRs): the hallmark of an ingenious antiviral defense mechanism in prokaryotes. Biological Chemistry 2011, 392, 277-289, https://doi.org/10.1515/BC.2011.042.

16. Horvath, P.; Barrangou, R. CRISPR/Cas, the Immune System of Bacteria and Archaea. Science 2010, 327 , 167-70, https://doi.org/10.1126/science.1179555.

17. Marraffini, L.A.; Sontheimer, E.J. CRISPR interference: RNA-directed adaptive immunity in bacteria and archaea. Nature Reviews Genetics 2010, 11, 181-190, https://doi.org/10.1038/nrg2749.

18. Høiby, N. New antimicrobials in the management of cystic fibrosis. Journal of Antimicrobial Chemotherapy 2002, 49, 235-238, https://doi.org/10.1093/jac/49.2.235.

19. Sorek, R.; Kunin, V.; Hugenholtz, P. CRISPR — a widespread system that provides acquired resistance against phages in bacteria and archaea. Nature Reviews Microbiology 2008, 6, 181-186, https://doi.org/10.1038/nrmicro1793.

20. Westra, E.R.; Buckling, A.; Fineran, P.C. CRISPR-Cas systems: beyond adaptive immunity. Nature Reviews Microbiology 2014, 12, 317-326, https://doi.org/10.1038/nrmicro3241.

21. Bozic, B.; Repac, J.; Djordjevic, M. Endogenous Gene Regulation as a Predicted Main Function of Type IE CRISPR/Cas System in E. coli. Molecules 2019, 24, https://doi.org/10.3390/molecules24040784.

22. Stern, A.; Keren, L.; Wurtzel, O.; Amitai, G.; Sorek, R. Self-targeting by CRISPR: gene regulation or autoimmunity? Trends in Genetics 2010, 26, 335-340, https://doi.org/10.1016/j.tig.2010.05.008.

23. Marraffini, L.A.; Sontheimer, E.J. Self versus non-self discrimination during CRISPR RNA-directed immunity. Nature 2010, 463, 568-571, https://doi.org/10.1038/nature08703.

24. Watters, K.E.; Fellmann, C.; Bai, H.B.; Ren, S.M.; Doudna, J.A. Systematic discovery of natural CRISPRCas12a inhibitors. Science 2018, 362, 236-239, https://doi.org/10.1126/science.aau5138.

25. McDonald, N.D.; Regmi, A.; Morreale, D.P.; Borowski, J.D.; Boyd, E.F. CRISPR-Cas systems are present predominantly on mobile genetic elements in Vibrio species. BMC Genomics 2019, 20, https://doi.org/10.1186/s12864-019-5439-1.

26. Kunin, V.; Sorek, R.; Hugenholtz, P. Evolutionary conservation of sequence and secondary structures in CRISPR repeats. Genome Biology 2007, 8, https://doi.org/10.1186/gb-2007-8-4-r61.

27. Bondy-Denomy, J.; Davidson, A.R. To acquire or resist: the complex biological effects of CRISPR-Cas systems. Trends in Microbiology 2014, 22, 218-225, https://doi.org/10.1016/j.tim.2014.01.007.

28. Louwen, R.; Horst-Kreft, D.; de Boer, A.G.; van der Graaf, L.; de Knegt, G.; Hamersma, M.; Heikema, A.P.; Timms, A.R.; Jacobs, B.C.; Wagenaar, J.A.; Endtz, H.P.; van der Oost, J.; Wells, J.M.; Nieuwenhuis, E.E.S.; van Vliet, A.H.M.; Willemsen, P.T.J.; van Baarlen, P.; van Belkum, A. A novel link between Campylobacter jejuni bacteriophage defence, virulence and Guillain-Barré syndrome. European Journal of Clinical Microbiology \& Infectious Diseases 2013, 32, 207-226, https://doi.org/10.1007/s10096-012-1733-4.

29. Babu, M.; Beloglazova, N.; Flick, R.; Graham, C.; Skarina, T.; Nocek, B.; Gagarinova, A.; Pogoutse, O.; Brown, G.; Binkowski, A.; Phanse, S.; Joachimiak, A.; Koonin, E.; Savchenko, A.; Emili, A.; Greenblatt, J.; Edwards, A.; Yakunin, A. A dual function of the CRISPR-Cas system in bacterial antivirus immunity and DNA repair. Molecular Microbiology 2011, 79, 484-502, https://doi.org/10.1111/j.13652958.2010.07465.x.

30. Grissa, I.; Vergnaud, G.; Pourcel, C. CRISPRFinder: a web tool to identify clustered regularly interspaced short palindromic repeats. Nucleic Acids Res 2007, 35, W52-W57, https://doi.org/10.1093/nar/gkm360.

31. Koonin, E.V. Open questions: CRISPR biology. BMC Biology 2018, 16, https://doi.org/10.1186/s12915018-0565-9.

32. Lyons, C.; Raustad, N.; Bustos, M.A.; Shiaris, M. Incidence of Type II CRISPR1-Cas Systems in Enterococcus Is Species-Dependent. PLOS ONE 2015, 10, https://doi.org/10.1371/journal.pone.0143544. 
33. Hullahalli, K.; Rodrigues, M.; Nguyen, U.T.; Palmer, K. An Attenuated CRISPR-Cas System in Enterococcus faecalis Permits DNA Acquisition. mBio 2018, 9, e00414-00418, e00414-18, https://doi.org/10.1128/mBio.00414-18.

34. Palmer, K.L.; Gilmore, M.S. Multidrug-Resistant Enterococci Lack CRISPR-cas. mBio 2010, 1, e0022700210, https://doi.org/10.1128/mBio.00227-10.

35. Veesenmeyer, J.L.; Andersen, A.W.; Lu, X.; Hussa, E.A.; Murfin, K.E.; Chaston, J.M.; Dillman, A.R.; Wassarman, K.M.; Sternberg, P.W.; Goodrich-Blair, H. NilD CRISPR RNA contributes to Xenorhabdus nematophila colonization of symbiotic host nematodes. Molecular Microbiology 2014, 93, 1026-1042, https://doi.org/10.1111/mmi.12715.

36. Jansen, R.; Embden, J.D.A.v.; Gaastra, W.; Schouls, L.M. Identification of genes that are associated with DNA repeats in prokaryotes. Molecular Microbiology 2002, 43, 1565-1575, https://doi.org/10.1046/j.13652958.2002.02839.x.

37. Horvath, P.; Coûté-Monvoisin, A.-C.; Romero, D.A.; Boyaval, P.; Fremaux, C.; Barrangou, R. Comparative analysis of CRISPR loci in lactic acid bacteria genomes. International Journal of Food Microbiology 2009, 131, 62-70, https://doi.org/10.1016/j.ijfoodmicro.2008.05.030.

38. Andersen, J.M.; Shoup, M.; Robinson, C.; Britton, R.; Olsen, K.E.P.; Barrangou, R. CRISPR Diversity and Microevolution in Clostridium difficile. Genome Biology and Evolution 2016, 8, 2841-2855, https://doi.org/10.1093/gbe/evw203.

39. Hidalgo, C.; Crawley, A.; Sanchez, B.; Barrangou, R. Characterization and Exploitation of CRISPR Loci in Bifidobacterium longum. Front. Microbiol. 2017, 8, https://doi.org/10.3389/fmicb.2017.01851.

40. García, J.; De la Herrán, R.; Robles, F.; Navajas, R.; Ruiz, C. Detection and variability analyses of CRISPRlike loci in the H. pylorigenome. PeerJ. 2017, 7, https://doi.org/10.7717/peerj.6221.

41. Hofacker, I.L. Vienna RNA secondary structure server. Nucleic Acids Res 2003, 31, 3429-3431, https://doi.org/10.1093/nar/gkg599.

42. Mojica, F.J.M.; Díez-Villaseñor, C.s.; García-Martínez, J.; Soria, E. Intervening Sequences of Regularly Spaced Prokaryotic Repeats Derive from Foreign Genetic Elements. Journal of Molecular Evolution 2005, 60, 174-182, https://doi.org/10.1007/s00239-004-0046-3.

43. Barrangou, R.; Fremaux, C.; Deveau, H.; Richards, M.; Boyaval, P.; Moineau, S.; Romero, D.A.; Horvath, P. CRISPR Provides Acquired Resistance Against Viruses in Prokaryotes. Science 2007, 315, 1709-1712, DOI: https://doi.org/10.1126/science.1138140.

44. Viswanathan, P.; Murphy, K.; Julien, B.; Garza, A. \& Kroos, L. Regulation of dev, an operon that includes genes essential for Myxococcus xanthus development and CRISPR-associated genes and repeats. Journal of bacteriology 2007, 189, 3738-3750, https://doi.org/10.1128/JB.00187-07.

45. Zheng, Y.; Li, J.; Wang, B.; Han, J.; Hao, Y.; Wang, S.; Ma, X.; Yang, S.; Ma, L.; Yi, L.; Peng, W. Endogenous Type I CRISPR-Cas: From Foreign DNA Defense to Prokaryotic Engineering. Front. Bioeng. Biotechnol. 2020, 8, https://doi.org/10.3389/fbioe.2020.00062.

46. Vercoe, R.B.; Chang, J.T.; Dy, R.L.; Taylor, C.; Gristwood, T.; Clulow, J.S.; Richter, C.; Przybilski, R.; Pitman, A.R.; Fineran, P.C. Cytotoxic Chromosomal Targeting by CRISPR/Cas Systems Can Reshape Bacterial Genomes and Expel or Remodel Pathogenicity Islands. PLOS Genetics 2013, 9, https://doi.org/10.1371/journal.pgen.1003454.

47. Louwen, R.; Horst-Kreft, D.; de Boer, A.G.; van der Graaf, L.; de Knegt, G.; Hamersma, M.; Heikema, A.P.; Timms, A.R.; Jacobs, B.C.; Wagenaar, J.A.; Endtz, H.P.; van der Oost, J.; Wells, J.M.; Nieuwenhuis, E.E.S.; van Vliet, A.H.M.; Willemsen, P.T.J.; van Baarlen, P.; van Belkum, A. A novel link between Campylobacter jejuni bacteriophage defence, virulence and Guillain-Barré syndrome. European Journal of Clinical Microbiology \& Infectious Diseases 2013, 32, 207-226, https://doi.org/10.1007/s10096-012-1733-4.

48. Mohamadi, S.; Zaker Bostanabad, S.; Mirnejad, R. CRISPR Arrays: A Review on Its Mechanism. Journal of Applied Biotechnology Reports 2020, 7, 81-86, https://doi.org/10.30491/JABR.2020.109380.

49. Medina-Aparicio, L.; Dávila, S.; Rebollar-Flores, J.E.; Calva, E.; Hernández-Lucas, I. The CRISPR-Cas system in Enterobacteriaceae. Pathogens and Disease 2018, 76, https://doi.org/10.1093/femspd/fty002.

50. Adli, M. The CRISPR tool kit for genome editing and beyond. Nature Communications 2018, 9 , https://doi.org/10.1038/s41467-018-04252-2.

51. Jaganathan, D.; Ramasamy, K.; Sellamuthu, G.; Jayabalan, S.; Venkataraman, G. CRISPR for Crop Improvement: An Update Review. Front. Plant Sci. 2018, 9, https://doi.org/10.3389/fpls.2018.00985.

52. Sampson, T.R.; Saroj, S.D.; Llewellyn, A.C.; Tzeng, Y.-L.; Weiss, D.S. A CRISPR/Cas system mediates bacterial innate immune evasion and virulence. Nature 2013, 497, 254-257, https://doi.org/10.1038/nature12048.

53. Dugar, G.; Leenay, R.T.; Eisenbart, S.K.; Bischler, T.; Aul, B.U.; Beisel, C.L.; Sharma, C.M. CRISPR RNADependent Binding and Cleavage of Endogenous RNAs by the Campylobacter jejuni Cas9. Molecular Cell 2018, 69, 893-905.e897, https://doi.org/10.1016/j.molcel.2018.01.032.

54. Gunderson, F.; Cianciotto, N. The CRISPR-associated gene cas2 of Legionella pneumophila is required for intracellular infection of amoebae. MBio 2013, 4, 74-13, https://doi.org/10.1128/mBio.00074-13.

55. Watanabe, S.; Cui1, B.; Kiga, K.; Aiba1, Y.; Tan, X.; Sato'o1, Y.; Kawauchi1, M.; Boonsiri1, T.; Thitiananpakorn, K.; Taki1, Y.; Li, F.; Azam, A.; Nakada, Y.; Sasahara, T.; Cuil, L. Composition and 
Diversity of CRISPR-Cas13a Systems in the Genus Leptotrichia. Front. Microbiol. 2019, 10, https://doi.org/10.3389/fmicb.2019.02838.

56. Mojica, F.J.M.; Rodriguez-Valera, F. The discovery of CRISPR in archaea and bacteria. The FEBS Journal 2016, 283, 3162-3169, https://doi.org/10.1111/febs.13766.

57. Gomgnimbou, M.K.; Abadia, E.; Zhang, J.; Refrégier, G.; Panaiotov, S.; Bachiyska, E.; Sola, C. "Spoligoriftyping," a Dual-Priming-Oligonucleotide-Based Direct-Hybridization Assay for Tuberculosis Control with a Multianalyte Microbead-Based Hybridization System. Journal of Clinical Microbiology 2012, 50, 3172-3179, https://doi.org/10.1128/JCM.00976-12.

58. Klotoe, B.J.; Kacimi, S.; Costa-Conceicão, E.; Gomes, H.M.; Barcellos, R.B.; Panaiotov, S.; Haj Slimene, D.; Sikhayeva, N.; Sengstake, S.; Schuitema, A.R.; Akhalaia, M.; Alenova, A.; Zholdybayeva, E.; Tarlykov, P.; Anthony, R.; Refrégier, G.; Sola, C. Genomic characterization of MDR/XDR-TB in Kazakhstan by a combination of high-throughput methods predominantly shows the ongoing transmission of L2/Beijing 9432 central Asian/Russian clusters. BMC Infectious Diseases 2019, 19, https://doi.org/10.1186/s12879-0194201-2.

59. Knott, G.J.; Doudna, J.A. CRISPR-Cas guides the future of genetic engineering. Science 2018, 361, 866869, https://doi.org/10.1126/science.aat5011.

60. Sasnauskas, G.; Siksnys, V. CRISPR adaptation from a structural perspective. Current Opinion in Structural Biology 2020, 65, 17-25, https://doi.org/10.1016/j.sbi.2020.05.015.

61. Mosterd, C.; Rousseau, G.M.; Moineau, S. A short overview of the CRISPR-Cas adaptation stage. Canadian journal of microbiology 2020, 1-12, https://doi.org/10.1139/cjm-2020-0212.

62. Faure, G.; Shmakov, S.; Makarova, K.; Wolf, Y.; Crawley, A.; Barrangou, R. \& Koonin, E. Comparative genomics and evolution of trans-activating RNAs in Class 2 CRISPR-Cas systems. RNA Biology 2019, 16:4, 435-448, 10.1080/15476286.2018.1493331

63. Refrégier, G.; Abadia, E.; Matsumoto, T.; Ano, H.; Takashima, T.; Tsuyuguchi, I.; Aktas, E.; Cömert, F.; Gomgnimbou, M.K.; Panaiotov, S.; Phelan, J.; Coll, F.; McNerney, R.; Pain, A.; Clark, T.G.; Sola, C. Turkish and Japanese Mycobacterium tuberculosis sublineages share a remote common ancestor. Infection, Genetics and Evolution 2016, 45, 461-473, https://doi.org/10.1016/j.meegid.2016.10.009.

64. Molina-Moya, B.; Gomgnimbou, M.K.; Spinasse, L.; Obasanya, J.; Oladimeji, O.; Dacombe, R.; Edwards, T.; Daragon, X.-O.; Lawson, L.; Abdurrahman, S.T.; Cuevas, L.E.; Dominguez, J.; Sola, C. Mycobacterium tuberculosis complex genotypes circulating in Nigeria based on spoligotyping obtained from Ziehl-Neelsen stained slides extracted DNA. PLOS Neglected Tropical Diseases 2018, 12, https://doi.org/10.1371/journal.pntd.0006242.

65. Bossi, L., Figueroa-Bossi, N., Bouloc, P. \& Boudvillain, M. Regulatory interplay between small RNAs and transcription termination factor Rho. Biochimica et Biophysica Acta (BBA) - Gene Regulatory Mechanisms 2020, 194546, 10.1016/j.bbagrm.2020.194546

66. Schwarz, D.S.; Hutvágner, G.; Du, T.; Xu, Z.; Aronin, N.; Zamore, P.D. Asymmetry in the Assembly of the RNAi Enzyme Complex. Cell 2003, 115, 199-208, https://doi.org/10.1016/s0092-8674(03)00759-1.

67. Behler, J., \& Hess, W. R. Approaches to Study CRISPR RNA Biogenesis and the Key Players Involved. Methods 2019, 172:12-26, 10.1016/j.ymeth.2019.07.015

68. Nussenzweig, P. M. \& Marraffini, L. A. Molecular Mechanisms of CRISPR-Cas Immunity in Bacteria. Annual Review of Genetics 2020, 54(1), 10.1146/annurev-genet-022120-112523

69. Hille, F.; Richter, H.; Wong, S.P.; Bratovič, M.; Ressel, S.; Charpentier, E. The Biology of CRISPR-Cas: Backward and Forward. Cell 2018, 172, 1239-1259, https://doi.org/10.1016/j.cell.2017.11.032.

70. Huang, X.; Chen, Z. \& Liu, Y. RNAi-mediated control of CRISPR functions. Theranostics 2020, 10(15): 6661-6673, 10.7150/thno.44880

71. Ratner, H.K.; Sampson, T.R.; Weiss, D.S. I can see CRISPR now, even when phage are gone: a view on alternative CRISPR-Cas functions from the prokaryotic envelope. Current opinion in infectious diseases 2015, 28, 267-274, https://doi.org/10.1097/QCO.0000000000000154.

72. Wiedenheft, B.; Bondy-Denomy, J. CRISPR control of virulence in Pseudomonas aeruginosa. Cell Research 2017, 27, 163-164, https://doi.org/10.1038/cr.2017.6.

73. Bernal-Bernal, D.; Abellón-Ruiz, J.; Iniesta, A.A.; Pajares-Martínez, E.; Bastida-Martínez, E.; Fontes, M.; Padmanabhan, S.; Elías-Arnanz, M. Multifactorial control of the expression of a CRISPR-Cas system by an extracytoplasmic function $\sigma /$ anti- $\sigma$ pair and a global regulatory complex. Nucleic Acids Res 2018, 46, 67266745, https://doi.org/10.1093/nar/gky475. 